05;07

\title{
Особенности расчета и исследования вольт-эрстедной характеристики анизотропного магниторезистивного датчика
}

\author{
() В.В. Амеличев ${ }^{1}$, Д.А. Жуков ${ }^{1, \uparrow, ~ С . И . ~ К а с а т к и н ~}{ }^{2}$, Д.В. Костюк ${ }^{1}$, О.П. Поляков ${ }^{2,3}$, \\ П.А. Поляков ${ }^{3}$, В.С. Шевцов ${ }^{2,3}$ \\ ${ }^{1}$ НПК „Технологический центр“, Москва, Зеленоград, Россия \\ ${ }^{2}$ Институт проблем управления им. В.А. Трапезникова РАН, Москва, Россия \\ ${ }^{3}$ Московский государственный университет им. М.В. Ломоносова, Москва, Россия \\ ๑ E-mail: D.Zhukov@tcen.ru
}

Поступило в Редакцию 30 июня 2020r.

В окончательной редакции 11 декабря 2020 г.

Принято к публикации 18 февраля 2021 г.

\begin{abstract}
Представлены результаты экспериментальных и теоретических исследований влияния величины собственного тока на характеристики анизотропных магниторезистивных датчиков магнитного поля на основе сплава FeNiCo со структурой типа „,barber-pole“. Установлено существенное различие вольт-эрстедных характеристик прямого и обратного хода при увеличении собственного тока, вызванного входным напряжением питания, при достаточно больших внешних магнитных полях. Проведен теоретический расчет вольтэрстедной характеристики в рамках модели одномерной неоднородности распределения намагниченности; полученная характеристика совпадает с экспериментальными данными для прямого хода.
\end{abstract}

Ключевые слова: теория микромагнетизма, магниторезистивный эффект, преобразователь магнитного поля, магниторезистивная наноструктура.

DOI: 10.21883/PJTF.2021.10.50967.18445

Датчики магнитного поля (ДМП) на основе магниторезистивных (MP) нанополосок с токовой неоднородностью низкорезистивных шунтов „,barber-pole“ продолжают активно исследоваться с целью улучшения их характеристик [1-4]. В настоящей работе экспериментально и теоретически исследовано влияние магнитного поля собственного тока ДМП, вызванного напряжением питания $\left(V_{i n}\right)$, на его вольт-эрстедную характеристику (ВЭХ) и установлено влияние этого фактора на чувствительность, нелинейность и коэрцитивность.

Датчик магнитного поля на основе анизотропного магниторезистивного эффекта (АМР ДМП) состоит из системы магниторезистивных нанополосок, соединенных в мостовую схему. Эскиз фрагмента МР-полоски с низкорезистивными шунтами представлен на рис. 1. Низкорезистивные полоски-шунты располагаются на МР-элементе под углом $45^{\circ}$ относительно оси легкого намагничивания (ОЛН), которая направлена вдоль длинной стороны МР-элемента. Направление тока в МР-элементе между низкорезистивными шунтами составляет угол $45^{\circ}$ относительно его ОЛН при отсутствии внешнего поля. Внешнее магнитное поле, направленное перпендикулярно ОЛН МР-элемента, приводит к изменению его сопротивления.

Конструкция АМР ДМП включает тонкопленочные магниторезистивные элементы, соединенные в мостовую схему, и планарные катушки подмагничивания. В НПК „Технологический центр“ изготовлены и исследованы АМР-преобразователи со следующими параметрами магниторезисторов: ширина МР-плоски $10 \mu \mathrm{m}$, расстояние между низкорезистивными шунтами $5 \mu \mathrm{m}$, их ширина $3 \mu \mathrm{m}$. При объединении МР-полосок в мостовую схему [3-5] образуется четырехполюсник, на входные полюса которого подается входное напряжение $V_{i n}$. Если поместить АМР ДМП во внешнее магнитное поле $\mathbf{H}$, направленное перпендикулярно полоскам [5], то под действием поля произойдет отклонение вектора намагниченности М в каждой малой области полоски на некоторый угол $\theta$. Это приведет к изменению сопротивления данной области в соответствии с анизотропным магниторезистивным эффектом [1] и, следовательно, к изменению сопротивления МР-полосок АМР ДМП и изменению выходного напряжения $V_{\text {out }}$. Зная зависимость напряжения $V_{\text {out }}$ от внешнего магнитного поля Н (вольт-эрстедная характеристика), можно по измеренному значению выходного напряжения $V_{\text {out }}$ определить напряженность магнитного поля $\mathbf{H}$.

Для теоретического расчета ВЭХ необходимо знать пространственное распределение вектора намагниченности М и плотности тока в полоске. Наибольшую сложность представляет решение микромагнитной задачи, которая в рассматриваемом варианте не может быть решена в общем случае, несмотря на большой прогресс, достигнутый в решении этой проблемы для магнитных образцов значительно меньшего размера [6]. В данной работе эта задача для рассматриваемых магнитных полосок решается в предположении, что в них не зарождаются магнитные домены и субдоменные структуры, а пространственное распределение намагниченности можно считать одномерным в рамках формализма, разработанного в работе [7]. Следует отметить, что при этих ограничениях микромагнитную задачу можно решить и 
другими известными методами, например с помощью пакета программ ООММF [8]. Однако время расчета при использовании этого пакета с той же точностью будет приблизительно в $10^{5}$ раз больше.

Равновесное распределение вектора намагниченности М находится как решение вариационной задачи на нахождение минимума полной магнитной энергии ферромагнетика относительно вариации $\delta \mathbf{M}[9]$ :

$$
W=\int_{V}\left(w_{a}+w_{m}+w_{H}\right) d V=\min .
$$

Здесь $w_{a}$ - плотность энергии магнитной анизотропии,

$$
w_{a}=K\left(M^{2}-(\mathbf{M} \cdot \mathbf{n})^{2}\right) / M^{2},
$$

где $K-$ константа одноосной анизотропии, $\mathbf{n}-$ единичный вектор, направленный вдоль оси легкого намагничивания.

Величина $w_{m}$ - плотность магнитостатической энергии, определяемая выражением

$$
w_{m}=-\frac{1}{2}\left(\mathbf{M} \cdot \mathbf{H}_{m}\right),
$$

где $\mathbf{H}_{m}-$ магнитное поле, создаваемое объемными и поверхностными магнитными „зарядами“, называемое магнитостатическим или размагничивающим полем. Размагничивающее поле $\mathbf{H}_{m}$ определяется уравнениями магнитостатики

$$
\begin{gathered}
{\left[\boldsymbol{\nabla} \times \mathbf{H}_{m}\right]=0,} \\
\nabla \cdot\left(\mathbf{H}_{m}+4 \pi \mathbf{M}\left(\mathbf{r}^{\prime}\right)\right)=0 .
\end{gathered}
$$

Решение уравнений магнитостатики можно представить в виде

$$
\mathbf{H}_{m}=\nabla \cdot \int_{V} \frac{\boldsymbol{\nabla} \cdot \mathbf{M}\left(\mathbf{r}^{\prime}\right)}{\left|\mathbf{r}-\mathbf{r}^{\prime}\right|} d \mathbf{r}^{\prime}-\nabla \cdot \int_{S} \frac{\mathbf{M}\left(\mathbf{r}^{\prime}\right)}{\left|\mathbf{r}-\mathbf{r}^{\prime}\right|} d S^{\prime},
$$

где $V$ - объем, $S$ - поверхность магнетика.

Последнее слагаемое в (1) представляет собой плотность зеемановской энергии:

$$
w_{H}=-(\mathbf{M} \cdot \mathbf{H}) \text {. }
$$

Следуя [7], сведем континуальную модель к дискретной, разделяя магнитную полоску на систему $N$ ячеек (длинных одномерных полосок), в пределах которых распределение намагниченности считается однородным. Тогда система (1)-(7) сведется к системе $N$ уравнений, для решения которой можно использовать эффективные математические методы [7]. В исследуемых МР-полосках распределение тока между низкорезистивными шунтами (рис. 1) будет неоднородным. В первом приближении эту неоднородность можно учесть как отсутствие токов в треугольных областях на краях вдоль полоски (на рис. 1 эта область обозначена штриховой линией). Результаты расчета и экспериментального измерения ВЭХ для ДМП на основе МР-полосок с токовой неоднородностью низкорезистивных шунтов с параметрами,

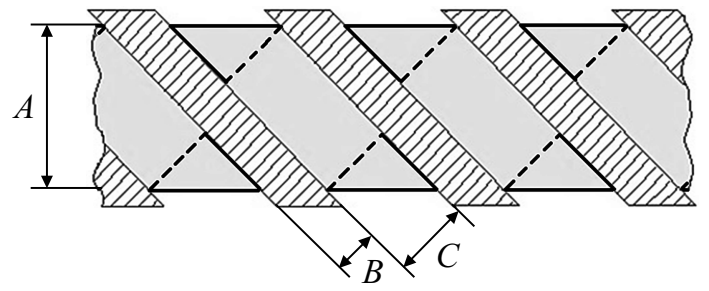

Рис. 1. Фрагмент МР-полоски. $A-$ ширина МР-полоски, $B$ - ширина низкорезистивного шунта, $C$ - расстояние между низкорезистивными шунтами в МР-полоске.

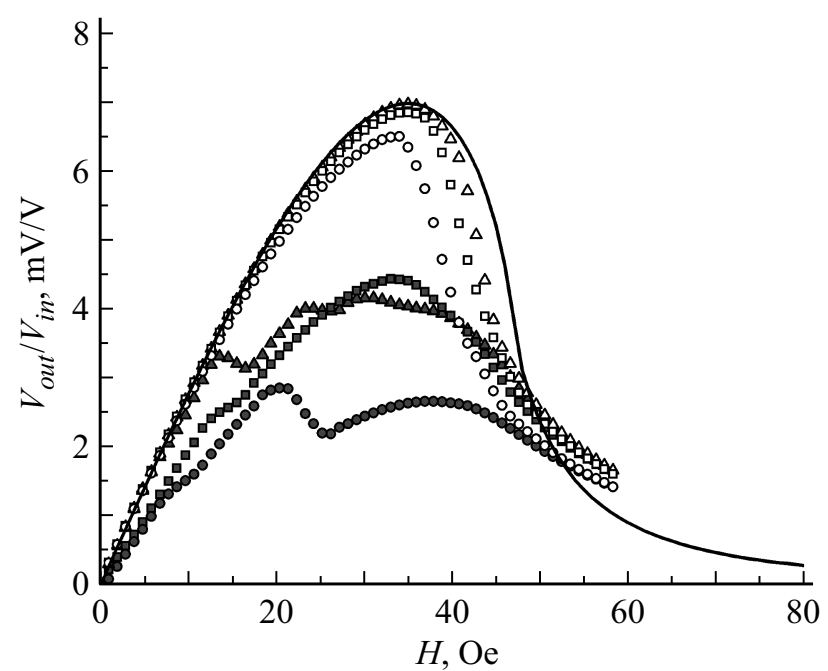

Рис. 2. Экспериментальные зависимости ВЭХ от величины входного напряжения ДМП при изменении внешнего поля в пределах 58 Ое. Треугольниками отмечены значения при $V_{i n}=1 \mathrm{~V}$, квадратами - при $5 \mathrm{~V}$, кружками - при $9.5 \mathrm{~V}$. Светлые символы соответствуют увеличению магнитного поля, серые - уменьшению. Сплошная кривая — теоретический расчет.

указанными выше, представлены на рис. 2. Сплошной линией показана теоретическая кривая, рассчитанная в рамках предложенной модели одномерной неоднородности распределения намагниченности в полоске [7]. Результаты экспериментального измерения зависимости ВЭХ от величины собственного тока АМР ДМП, вызванного различными напряжениями $\left(V_{i n}=1,5\right.$ и $\left.9.5 \mathrm{~V}\right)$, при увеличении напряженности магнитного поля от 0 до 58 Ое и при обратном уменьшении магнитного поля до нуля представлены символами на рис. 2.

Из рис. 2 следует, что предложенная теоретическая модель достаточно точно описывает прямой ход ВЭХ, но при обратном ходе (уменьшении магнитного поля) экспериментальная кривая идет заметно ниже. Это свидетельствует о значительном гистерезисе МР-полосок в данном диапазоне изменения магнитного поля. Предполагается, что при уменьшении магнитного поля в МР-полосках возникают продольные магнитные домены, которые уменьшают разность МР-сопротивления в противоположных плечах мостовой схемы, что приводит 


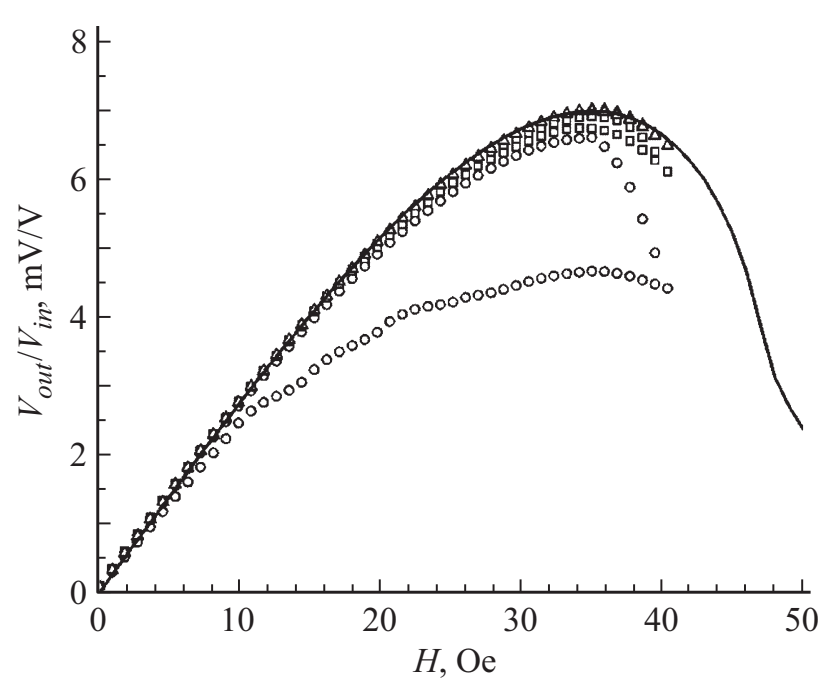

Рис. 3. Экспериментальная зависимость ВЭХ от величины входного напряжения ДМП при изменении внешнего поля в пределах 40 Ое. Треугольниками отмечены значения при $V_{i n}=1 \mathrm{~V}$, квадратами - при $5 \mathrm{~V}$, кружками - при $9.5 \mathrm{~V}$.

к снижению выходного напряжения. При увеличении магнитного поля выше 40 Ое наблюдается отклонение теоретической зависимости от экспериментальной. Это, возможно, обусловлено неточным учетом распределения токов вдоль краев МР-полоски, так как при больших полях распределение намагниченности в краевых областях вносит определяющий вклад в изменение МРсопротивления.

На рис. 3 представлена ВЭХ при меньшем диапазоне изменения внешнего магнитного поля от 0 до 40 Ое и обратно при тех же значениях $V_{i n}$. Из данной характеристики следует, что при малом входном напряжении $V_{\text {in }}=1 \mathrm{~V}$ теоретические и экспериментальные данные совпадают с высокой точностью и обладают низким гистерезисом. При увеличении напряжения $V_{i n}$ до 5 и $9.5 \mathrm{~V}$ проявляется гистерезис и наблюдается уменышение экспериментальной характеристики по сравнению с теоретической при больших значениях внешнего магнитного поля. При магнитном поле до 10 Ое теоретические и экспериментальные данные характеризуются хорошим совпадением.

Таким образом, проведенные в работе исследования показали наличие гистерезиса ВЭХ АМР-датчика со структурой типа „barber-pole“, величина которого существенно зависит от величины собственного тока, вызванного входным напряжением, и напряженности внешнего магнитного поля. Теоретические расчеты ВЭХ, основанные на модели одномерной неоднородности распределения намагниченности [7], совпадают с экспериментальными кривыми при увеличении внешнего магнитного поля, но не объясняют особенности кривой обратного хода (гистерезис) при больших собственных токах и магнитных полях при уменьшении внешнего магнитного поля.

\section{Благодарности}

Исследование проводилось с использованием оборудования ЦКП „Функциональный контроль и диагностика микро- и наносистемной техники“ на базе НПК „Технологический центр“.

\section{Финансирование работы}

Работа поддержана Фондом развития теоретической физики и математики „БАЗИС“.

\section{Конфликт интересов}

Авторы заявляют, что у них нет конфликта интересов.

\section{Список литературы}

[1] C. Wang, W. Su, Z. Hu, J. Pu, M. Guan, B. Peng, L. Li, W. Ren, Z. Zhou, Z. Jiang, M. Liu, IEEE Trans. Magn., 54 (11), 2301103 (2018). DOI: 10.1109/TMAG.2018.2846758

[2] P.V. Sreevidya, J. Khan, H.C. Barshilia, C.M. Ananda, P. Chowdhury, J. Magn. Magn. Mater., 448, 298 (2018). DOI: $10.1016 /$ j.jmmm.2017.08.064

[3] W. Su, Z. Wang, T. Wen, Z. Hu, J. Wu, Z. Zhou, M. Liu, IEEE Electron Dev. Lett., 40 (6), 969 (2019). DOI: 10.1109/LED.2019.2913506

[4] Д.А. Жуков, М.А. Куприянова, Ю.И. Мокринский, В.В. Амеличев, Д.В. Костюк, Д.В. Васильев, Е.П. Орлов, Нано- и микросистемная техника, 20 (10), 579 (2018). DOI: $10.17587 /$ nmst.20.579-584

[5] C.-J. Zhao, M. Li, J.-W. Li, L. Ding, J. Teng, G.-H. Yu, J. Magn. Magn. Mater., 368, 328 (2014).

[6] М.Н. Дубовик, В.В. Зверев, Б.Н. Филиппов, ЖЭТФ, 150 (1), 122 (2016). DOI: 10.7868/S0044451016070117

[7] В.С. Шевцов, О.П. Поляков, В.В. Амеличев, С.И. Касаткин, П.А. Поляков, Вестн. МГУ. Сер. 3: Физика, астрономия, № 5, 40 (2019).

[8] J.P. Adam, S. Rohart, J.P. Jamet, J. Ferré, A. Mougin, R. Weil, H. Bernas, G. Faini, Phys. Rev. B, 85 (21), 214417 (2012). DOI: $10.1103 /$ PhysRevB.85.214417

[9] B. Heinrich, J.F.Cochran, Adv. Phys., 42 (5), 523 (1993). 